\title{
Effect of VPAC1 Blockade on Adipose Tissue Formation and Composition in Mouse Models of Nutritionally Induced Obesity
}

\author{
H. Roger Lijnen, Kathleen Freson, and Marc F. Hoylaerts \\ Center for Molecular and Vascular Biology, KU Leuven, Campus Gasthuisberg, O \& N 1, Herestraat 49, P.O. Box 911, \\ B-3000 Leuven, Belgium \\ Correspondence should be addressed to H. Roger Lijnen, roger.lijnen@med.kuleuven.be
}

Received 14 December 2009; Accepted 18 May 2010

Academic Editor: Renato Pasquali

Copyright ( $\odot 2010 \mathrm{H}$. Roger Lijnen et al. This is an open access article distributed under the Creative Commons Attribution License, which permits unrestricted use, distribution, and reproduction in any medium, provided the original work is properly cited.

\begin{abstract}
Background. The pituitary adenylate cyclase activating polypeptide (PACAP) may affect adipogenesis and adipose tissue formation through interaction with its G-protein-coupled receptor VPAC1. Methods. We have used a monoclonal antibody (MAb 23A11) blocking VPAC1 in mouse models of nutritionally induced obesity. Results. Administration of MAb 23A11 (25 mg/kg body weight i.p. twice weekly) to 5-week old male $\mathrm{C} 57 \mathrm{Bl} / 6$ mice kept on a high-fat diet for 15 weeks had no significant effect on weight gain, nor on subcutaneous (SC) or gonadal (GON) adipose tissue mass, as compared to the control MAb 1C8. However, adipocyte hypertrophy was observed in SC adipose tissue of MAb 23A11 treated mice. In a second study, 24 weeks old obese mice were treated for 5 weeks with MAb 23A11, without effect on body weight or fat mass, as compared to treatment with MAb 1C8. In addition, MAb 23A11 had no significant effect on glucose tolerance or insulin resistance in lean or obese C57Bl/6 mice. Conclusion. Blocking VPAC1 does not significantly affect adipose tissue formation in mouse models of diet-induced obesity, although it may be associated with mild adipocyte hypertrophy.
\end{abstract}

\section{Introduction}

Obesity and its associated diseases such as noninsulin dependent diabetes, atherosclerosis, and cardiovascular disease are a main cause of mortality and morbidity. Development of adipose tissue is a complex process in which growth factors, cytokines, adipokines, proteases, and hormones control extensive modifications in adipogenesis, angiogenesis, and proteolytic remodeling of extracellular matrix [1]. Studies with gene-deficient mice have suggested a role for pituitary adenylate cyclase-activating polypeptide (PACAP) in adipose tissue development [2-4].

PACAP and vasoactive intestinal polypeptide (VIP) are two closely related neuropeptides that bind to their common G-protein-coupled receptors, VPAC1 and VPAC2, whereas PACAP in addition binds to the specific receptor PAC1. PACAP and VIP stimulate insulin secretion in a glucosedependent manner and also stimulate glucagon secretion [5]. PACAP is expressed in neural regions of the hypothalamus known to regulate appetite [6], and intracerebroventricular injection of PACAP reduced short-term food intake in mice [7]. The VPAC1 receptor is found in a wide variety of tissues, including adipose tissue [8], and its expression is markedly upregulated during differentiation of murine preadipocytes into mature adipocytes [9]. Also in primary rat adipocytes all three PACAP/VIP receptors are expressed [10]. Because of its integrative role in glucose and energy homeostasis, we have evaluated whether VPAC1 may play a role in adipogensis and adipose tissue formation. In this study, we have blocked the PACAP/VPAC1 pathway in mice kept on high-fat diet, using MAb 23A11 that was previously shown to inhibit VPAC1 signaling in mice $[11,12]$.

\section{Materials and Methods}

2.1. Diet Models. From birth on until 5 weeks of age, male $\mathrm{C} 57 \mathrm{Bl} / 6$ mice were kept on a standard fat diet (SFD) (KM-04-k12, Muracon, Carfil, Oud-Turnhout, Belgium, containing $13 \% \mathrm{kcal}$ as fat with a caloric value of $10.9 \mathrm{~kJ}$ per g). In a first study, 5 weeks old mice were kept on 
a high-fat diet (HFD) for 15 weeks (TD88137, Harlan Taklad, Zeist, The Netherlands, containing $42 \% \mathrm{kcal}$ as fat with a caloric value of $20.1 \mathrm{~kJ}$ per g). MAb $23 \mathrm{~A} 11$ with isotype IgG1 (a kind gift from ThromboGenics NV, Leuven, Belgium) or the control MAb 1C8 with matching isotype (directed against human $\mathrm{t}-\mathrm{PA}$, not crossreacting with murine t-PA) were injected intraperitoneally (i.p.) at a dose of $25 \mathrm{mg} / \mathrm{kg}$ body weight twice weekly during the 15 weeks experimental period ( $n=12$ each). In a second study, 24 weeks old obese mice (kept on HFD) were injected i.p. with MAb 23A11 $(n=12)$ or MAb 1C8 $(n=11)$ at a dose of $25 \mathrm{mg} / \mathrm{kg}$ body weight twice weekly during 5 weeks.

Mice were kept in microisolation cages on a $12 \mathrm{~h}$ day/night cycle, fed at libitum and weighed at weekly intervals. At the end of the experiment, the mice were killed by i.p. injection of $60 \mathrm{mg} / \mathrm{kg}$ sodium pentobarbital (Abbott Laboratories, North Chicago, IL). Blood was collected from the retroorbital sinus on trisodium citrate (final concentration $0.01 \mathrm{~mol} / \mathrm{L}$ ) and plasma was stored at $-20^{\circ} \mathrm{C}$. Epididymal (gonadal, GON) and inguinal (subcutaneous, SC) fat pads were removed and weighed; the weight of other organs was also recorded. Adipose tissue extracts and $10 \mu \mathrm{m}$ paraffin sections for histology were prepared as described [13].

Food intake was measured throughout the experimental period, and expressed as g per mouse and per day. All animal experiments were approved by the local ethical committee (KU Leuven, P03112) and performed in accordance with the NIH Guide for the Care and Use of Laboratory Animals (1996) and the guiding principles of the International Society of Thrombosis and Haemostasis [14].

2.2. Assays. Adipose tissue sections were stained with haematoxylin/eosin using a standard protocol, followed by signal amplification with the Tyramide Signal Amplification Cyanine System (Perkin Elmer, Boston, MA). The number of adipocytes and their mean size were determined by computer-assisted image analysis, using for each animal 3 to 5 areas in 4 different sections; the data were first averaged per section and then per animal.

The presence of MAb 23A11 in the adipose tissues was determined as follows: recombinant VPAC1 (GST fusion protein) was bound to microtiter plates coated with an antiGST antibody, and after incubation with the samples bound antibody was quantitated using an antimurine antibody. The assay was calibrated with purified MAb $23 \mathrm{~A} 11$ and data are expressed as $\mathrm{ng} / \mathrm{mg}$ adipose tissue.

Expression of VPAC1 mRNA in extracts of SC and GON adipose tissues was monitored by quantitative RTPCR, as described [15], using the gene expression assay Mm00449214_ml (Applied Biosystems, Foster City, CA). Data are normalized to the expression of Glyceraldehyde-3phosphate dehydrogenase (GAPDH; gene expression assay Mm00441818_A1; Applied Biosystems), and shown as $\Delta \mathrm{Ct}$ values using the 7500 Fast System SDS software (Applied Biosystems).
TABLE 1: Effect of VPAC1 blockade on development of adipose tissue in $\mathrm{C} 57 \mathrm{Bl} / 6$ mice kept on high-fat diet for 15 weeks.

\begin{tabular}{lcc}
\hline & MAb 23A11 & MAb 1C8 \\
\hline Body weight start $(\mathrm{g})$ & $16.7 \pm 0.37$ & $16.7 \pm 0.47$ \\
Body weight end $(\mathrm{g})$ & $40.1 \pm 1.2$ & $39.8 \pm 1.1$ \\
SC fat & & \\
$\quad$ Weight $(\mathrm{mg})$ & $1490 \pm 68$ & $1470 \pm 51$ \\
$\quad$ Adipocyte size $\left(\mu \mathrm{m}^{2}\right)$ & $4220 \pm 220^{*}$ & $3560 \pm 150$ \\
$\quad$ Adipocyte density $\left(\times 10^{-6} / \mu \mathrm{m}^{2}\right)$ & $250 \pm 14^{*}$ & $290 \pm 14$ \\
GON fat & & \\
$\quad$ Weight $(\mathrm{mg})$ & $2530 \pm 180$ & $2460 \pm 77$ \\
$\quad$ Adipocyte size $\left(\mu \mathrm{m}^{2}\right)$ & $5250 \pm 260$ & $5880 \pm 290$ \\
$\quad$ Adipocyte density $\left(\times 10^{-6} / \mu \mathrm{m}^{2}\right)$ & $200 \pm 9.8$ & $180 \pm 8.2$ \\
\hline
\end{tabular}

Data are means \pm SEM of 12 experiments in each group. ${ }^{*} P<.05$ versus MAb 1C8.

Blood glucose concentrations were determined using Glucocard strips (Menarini Diagnostics, Florence, Italy); trigyceride, total, HDL, and LDL cholesterol levels were evaluated using routine clinical assays. Blood cell analysis was performed on a Cell-Dyn 3500 R (Abbott Diagnostics, Abbott Park, IL). Insulin (Mercodia, Uppsala, Sweden) and leptin (R\&D Systems Europe, Lille, France) were measured with commercially available ELISAs. cAMP levels in adipose tissue extracts were measured by ELISA (Amersham cAMP Biotrak Enzyme immunoassay system RPN225).

Glucose tolerance and insulin resistance tests were performed, with a 3-4-day recovery period, in lean (on SFD) and obese (on HFD) male C57Bl/6 mice treated with MAb $23 \mathrm{~A} 11$ or MAb 1C8. Therefore, after an overnight fasting, glucose $(3 \mathrm{mg} / \mathrm{g}$ body weight $)$ or human insulin $(0.5 \mathrm{mU} / \mathrm{g})$ was injected into the peritoneal cavity. Blood was collected via the tail vein for glucose measurement before and at 15-120 minutes after injection. For detailed analysis, the areas under the curves (AUC) of glucose level versus time were determined. The MAbs were administered by two i.p. injections of $25 \mathrm{mg} / \mathrm{kg}$ body weight each, given at 4 days and 1 day before the test.

2.3. Statistical Analysis. Data are expressed as means \pm SEM. Statistical significance for differences between groups, analyzed by nonparametric Mann-Whitney U-testing, was set at $P<.05$.

\section{Results}

Body weight gain throughout the 15 weeks HFD feeding period was comparable for mice treated with MAb $23 \mathrm{~A} 11$ or MAb 1C8, resulting in comparable total body weights at the end of the study (Table 1). Food intake was identical in both groups (average of $3.4 \mathrm{~g} /$ day throughout the experimental period), compatible with a comparable feeding efficiency (weight gain normalized to caloric intake). Treatment with MAb 23A11 did not affect SC or GON adipose tissue mass, as compared to the control MAb 1C8. The weight of other 
TABLE 2: Effect of VPAC1 blockade on metabolic parameters in C57Bl/6 mice kept on high-fat diet for 15 weeks.

\begin{tabular}{lcc}
\hline & MAb 23A11 & MAb 1C8 \\
\hline Glucose (mg/dL) & $171 \pm 12$ & $175 \pm 11$ \\
Insulin (ng/mL) & $4.0 \pm 0.70$ & $3.1 \pm 0.41$ \\
Leptin (ng/mL) & $30 \pm 3.8$ & $29 \pm 2.1$ \\
Total cholesterol (mg/dL) & $185 \pm 18$ & $191 \pm 12$ \\
HDL cholesterol (mg/dL) & $149 \pm 13$ & $160 \pm 7.0$ \\
LDL cholesterol (mg/dL) & $29 \pm 5.0$ & $23 \pm 5.0$ \\
Triglycrides (mg/dL) & $38 \pm 5.0$ & $41 \pm 4.0$ \\
\hline
\end{tabular}

Data are means \pm SEM of 12 determinations in each group.

organs including liver, spleen, kidney, pancreas, lung, and heart was also comparable for mice in both groups (data not shown). Analysis of adipocyte size and density revealed the presence of significantly larger adipocytes at lower density in SC but not in GON adipose tissue of mice treated with MAb 23A11 (Table 1). Expression of VPAC1 mRNA in adipose tissues was not affected by treatment with MAb 23A11 $(\Delta \mathrm{Ct}$ of $13.44 \pm 0.21$ and $13.14 \pm 0.16$ for MAb 23A11 and MAb $1 \mathrm{C} 8$ treated $\mathrm{SC}$ adipose tissues, with corresponding values of $12.21 \pm 0.19$ and $12.51 \pm 0.13$ for GON adipose tissues). cAMP levels in adipose tissues were not significantly different for treatment with MAb 23A11 or MAb 1C8 (126 \pm 9.8 versus $117 \pm 7.6 \mathrm{fmol} / \mathrm{mg}$ SC tissue and $81 \pm 7.2$ versus 105 $\pm 12 \mathrm{fmol} / \mathrm{mg}$ GON tissue).

Metabolic parameters were very similar after treatment with both MAbs (Table 2). Glucose and insulin tolerance tests in lean or obese mice yielded similar results for $\mathrm{MAb}$ $23 \mathrm{~A} 11$ and MAb 1C8 treatment, as revealed by comparable area under the curve of glucose levels versus time (Table 3 ). In addition, fasting insulin levels measured at the start and end of the protocols and at $30 \mathrm{~min}$ after glucose injection in the glucose tolerance tests were comparable for MAb $23 \mathrm{~A} 11$ and MAb 1C8 treated lean as well as obese mice (data not shown).

In a separate study, obese mice (body weight 45-46 g) were treated for 5 weeks with MAb 23A11 or MAb 1C8. MAb 23A11 was detected in adipose tissue extracts, at a concentration of $4.0 \pm 0.61 \mathrm{ng} / \mathrm{mg}$ SC adipose tissue and $19 \pm 1.1 \mathrm{ng} / \mathrm{mg}$ GON adipose tissue. No differences were observed between MAb 23A11 and MAb 1C8 treated groups with respect to food intake $(3.71 \pm 0.09 \mathrm{~g} /$ day versus 3.75 $\pm 0.07 \mathrm{~g} /$ day $)$, body weight evolution $(45 \pm 1.2 \mathrm{~g}$ versus 45 $\pm 1.4 \mathrm{~g}$ at the end $), \mathrm{SC}(1820 \pm 100 \mathrm{mg}$ versus $1850 \pm$ $110 \mathrm{mg})$ or $\mathrm{GON}(2130 \pm 68 \mathrm{mg}$ versus $2330 \pm 140 \mathrm{mg})$ adipose tissue weight. As described above, the organ weights and metabolic parameters were also comparable for mice treated with either MAb (data not shown). Analysis of blood cell composition, including white blood cells, neutrophils, lymphocytes, monocytes, eosinophils, basophils, red blood cells, hemoglobin and hematocrit, did not reveal significant differences between both groups (data not shown), whereas the platelet count was somewhat higher in the MAb $23 \mathrm{~A} 11$ treated mice $(910 \pm 71 \mathrm{k} / \mu \mathrm{l}$ versus $764 \pm 52 \mathrm{k} / \mu \mathrm{l} ; P=.14)$.

\section{Discussion}

All 3 PACAP receptors are expressed in human adipose tissue [16] and in pancreatic islets [17], whereas VPAC1 is also found in a wide variety of other tissues [18]. In the present study we have evaluated whether blocking the VPAC1 pathway has the potential to affect adipose tissue development in mouse models of nutritionally induced obesity. This was achieved using MAb 23A11, an anti-VPAC1 antibody that was previously used to study the role of PACAP and its receptor VPAC1 in megakaryocyte maturation [12]. The epitope of MAb 23A11 is located in a region within the second and third extracellular loop (amino acids 278-373) of VPAC1; this second loop is involved in VPAC1 ligandmediated cAMP response [19]. The dose of MAb 23A11 used in mice in this study $(25 \mathrm{mg} / \mathrm{kg}$ i.p. twice weekly) is much higher than the dose used to efficiently block VPAC1 in studies on megakaryocyte maturation $(1 \mathrm{mg} / \mathrm{kg}$ s.c. 3 times per week); it is a dose commonly used to achieve a steady state antibody concentration in mice. It was well tolerated without apparent side effects. We have confirmed expression of VPAC1 in adipose tissues, as well as the presence of MAb 23A11. Administration of MAb 23A11, however, had no effect on cAMP levels in adipose tissues, which may be due to alternative compensatory mechanisms.

Platelet counts were moderately elevated, as observed previously with this MAb [12]. The main limitation of this study may be that inhibition of VPAC1 signaling by MAb $23 \mathrm{~A} 11$ could not be directly demonstrated at the level of the adipose tissue.

In mouse models of nutritionally induced obesity, evaluating either ongoing adipose tissue development or regression of established obesity, we did not find a marked effect of MAb 23A11 on food intake, body weight, or adipose tissue mass, nor on glucose tolerance or insulin resistance in lean or obese mice. However, adipocyte hypertrophy was observed in SC but not in GON adipose tissues of MAb 23A11 treated mice. Different behaviour of SC and GON adipose tissues is a common finding in many studies and may be related to differences in gene expression regulation, resulting in production of different amounts of adipokines [20]. We did not observe effects of MAb23A11 on circulating leptin concentrations, but it can not be excluded that intracellular leptin levels are higher in the hypertrophic adipocytes in SC fat.

Previous studies have reported that PACAP deficiency may affect food intake and/or adipose tissue development [2-4]. Thus, Nakata et al. [2] observed reduced food intake in PACAP-deficient mice if fed a high carbohydrate diet but not if fed a high-fat diet. Adams et al. [4], however, did not observe effects of PACAP deficiency using either diet; when fed normal chow and kept at $21^{\circ} \mathrm{C}$, the PACAP deficient mice were leaner than wild-type littermates due to decreased adiposity, and they displayed increased insulin sensitivity. Tomimoto et al. [3] found that PACAP deficient mice showed significant hypoinsulinemia, reduced food intake, lower body weight, and reduced white adipose tissue mass. The deficient mice also displayed increased insulin sensitivity in glucose and insulin tolerance tests. The main 
TABLE 3: Effect of VPAC1 blockade on glucose tolerance and insulin resistance in lean and obese mice.

\begin{tabular}{lcccc}
\hline & \multicolumn{2}{c}{ Lean $(n=10)$} & \multicolumn{2}{c}{ Obese $(n=6)$} \\
\hline Body weight $(\mathrm{g})$ & MAb 23A11 & MAb 1C8 & MAb 23A11 & MAb 1C8 \\
Glucose tolerance (AUC) & $19 \pm 0.36$ & $20 \pm 0.32$ & $45 \pm 1.4$ & $44 \pm 0.54$ \\
Insulin resistance (AUC) & $41,060 \pm 2,260$ & $44,125 \pm 3,260$ & $25,000 \pm 5,000$ & $30,800 \pm 2,700$ \\
\hline
\end{tabular}

For both MAbs, data are means \pm SEM of $n$ experiments in each group. AUC: area under the curve of glucose levels versus time

difference with our study is that PACAP antigen remains available in normal concentration in our mice, whereas only its interaction with VPAC1 is blocked. Using a PACAP receptor antagonist, [6-27] in genetically obese ob/ob mice it was shown that feeding activity, body weight or basal plasma glucose and insulin levels were not affected. However, the treatment induced impaired glucose tolerance, insulin sensitivity and a glycaemic response to feeding [21]. It is possible that this antagonist interferes with binding of PACAP to all 3 its receptors, whereas in our approach only VPAC1 is targeted. Our data obtained with MAb 23A11 thus allow to conclude that VPAC1 is not involved in glucose homeostasis or in regulation of insulin action, and that it does not play a functional role in regulation of food intake or adiposity. The mild adipocyte hypertrophy in SC adipose tissues after 15 weeks of treatment may be related to triglyceride accumulation, although this is not reflected by the circulating plasma levels. In addition, at the high concentration of MAb 23A11 used to saturate VPAC1 it is unlikely that VIP can still bind to VPAC1, suggesting that also the VIP/VPAC1 pathway does not play a major role. This suggests that such regulatory effects observed in other studies may be due to interaction of PACAP with VPAC2 or PAC1. This also implies that MAb 23A11, even when used at high concentration, is specific and does not affect the VPAC2 or PAC1 pathways allowing normal energy homeostasis, metabolism, and adipogenesis. In contrast, a recent study using a VPAC1 agonist (Lys15, Arg16, Leu27)$\operatorname{VIP}(1-7) \mathrm{GRF}(8-27)$ ) reported inhibition of food ingestion, prevention of the increases in body weight and white adipose tissue mass induced by high-fat diet feeding in control mice, as well as improved glucose tolerance [9]. This indicates that activation of the VPAC1 receptor may have a functional role, in contrast to blocking it with MAb 23A11.

The differences between studies may also be explained at least in part by different composition and timing of the diets, genetic background of the mice used, and specificity of the VPAC1 (ant)agonist.

\section{Acknowledgments}

Skillful technical assistance by L. Frederix, L. Cosemans, and B. Van Hoef is gratefully acknowledged. This study was supported financially by the Institute for the Promotion of Innovation through Science and Technology in Flanders (IWT-Vlaanderen; SBO project 040084). The Center for Molecular and Vascular Biology is supported by the "Excellentiefinanciering KULeuven" (Project EF/05/013).

\section{References}

[1] D. L. Crandall, G. J. Hausman, and J. G. Kral, "A review of the microcirculation of adipose tissue: anatomic, metabolic, and angiogenic perspectives," Microcirculation, vol. 4, no. 2, pp. 211-232, 1997.

[2] M. Nakata, D. Kohno, N. Shintani et al., "PACAP deficient mice display reduced carbohydrate intake and PACAP activates NPY-containing neurons in the rat hypothalamic arcuate nucleus," Neuroscience Letters, vol. 370, no. 2-3, pp. 252-256, 2004.

[3] S. Tomimoto, T. Ojika, N. Shintani et al., "Markedly reduced white adipose tissue and increased insulin sensitivity in adcyap1-deficient mice," Journal of Pharmacological Sciences, vol. 107, no. 1, pp. 41-48, 2008.

[4] B. A. Adams, S. L. Gray, E. R. Isaac, A. C. Bianco, A. J. VidalPuig, and N. M. Sherwood, "Feeding and metabolism in mice lacking pituitary adenylate cyclase-activating polypeptide," Endocrinology, vol. 149, no. 4, pp. 1571-1580, 2008.

[5] M. S. Winzell and B. Ahrén, "Role of VIP and PACAP in islet function," Peptides, vol. 28, no. 9, pp. 1805-1813, 2007.

[6] J. P. Segal, N. R. Stallings, C. E. Lee et al., "Use of laser-capture microdissection for the identification of marker genes for the ventromedial hypothalamic nucleus," Journal of Neuroscience, vol. 25, no. 16, pp. 4181-4188, 2005.

[7] J. E. Morley, M. Horowitz, P. M. K. Morley, and J. F. Flood, "Pituitary adenylate cyclase activating polypeptide (PACAP) reduces food intake in mice," Peptides, vol. 13, no. 6, pp. 11331135, 1992.

[8] J. C. Reubi, "In vitro evaluation of VIP/PACAP receptors in healthy and diseased human tissues: clinical implications," Annals of the New York Academy of Sciences, vol. 921, pp. 1$25,2000$.

[9] R. J. Yu, L. Zhang, T. H. Yi, et al., "In vivo anti-obesity effect of the agonist for receptor VPAC1," Acta Physiologica Sinica, vol. 60, pp. 751-758, 2008.

[10] L. Åkesson, B. Ahrén, G. Edgren, and E. Degerman, "VPAC2$\mathrm{R}$ mediates the lipolytic effects of pituitary adenylate cyclaseactivating polypeptide/vasoactive intestinal polypeptide in primary rat adipocytes," Endocrinology, vol. 146, no. 2, pp. 744-750, 2005.

[11] K. Freson, H. Hashimoto, C. Thys et al., "The pituitary adenylate cyclase-activating polypeptide is a physiological inhibitor of platelet activation," Journal of Clinical Investigation, vol. 113, no. 6, pp. 905-912, 2004.

[12] K. Freson, K. Peeters, R. De Vos et al., "PACAP and its receptor VPAC1 regulate megakaryocyte maturation: therapeutic implications," Blood, vol. 111, no. 4, pp. 1885-1893, 2008.

[13] H. R. Lijnen, E. Maquoi, D. Demeulemeester, B. Van Hoef, and D. Collen, "Modulation of fibrinolytic and gelatinolytic activity during adipose tissue development in a mouse model of nutritionally induced obesity," Thrombosis and Haemostasis, vol. 88, no. 2, pp. 345-353, 2002. 
[14] A. R. Giles, "Guidelines for the use of animals in biomedical research," Thrombosis and Haemostasis, vol. 58, no. 4, pp. 1078-1084, 1987.

[15] G. Voros, E. Maquoi, D. Demeulemeester, N. Clerx, D. Collen, and H. R. Lijnen, "Modulation of angiogenesis during adipose tissue development in murine models of obesity," Endocrinology, vol. 146, no. 10, pp. 4545-4554, 2005.

[16] Y. Wei and S. Mojsov, "Tissue specific expression of different human receptor types for pituitary adenylate cyclase activating polypeptide and vasoactive intestinal polypeptide: implications for their role in human physiology," Journal of Neuroendocrinology, vol. 8, no. 11, pp. 811-817, 1996.

[17] M. S. Winzell and B. Ahrén, "G-protein-coupled receptors and islet function-implications for treatment of type 2 diabetes," Pharmacology and Therapeutics, vol. 116, no. 3, pp. 437-448, 2007.

[18] J. C. Reubi, "In vitro evaluation of VIP/PACAP receptors in healthy and diseased human tissues: clinical implications," Annals of the New York Academy of Sciences, vol. 921, pp. 125, 2000.

[19] S. M. Knudsen, J. W. Tams, and J. Fahrenkrug, "Role of second extracellular loop in the function of human vasoactive intestinal polypeptide/pituitary adenylate cyclase activating polypeptide receptor 1 (hVPAC1R)," Journal of Molecular Neuroscience, vol. 14, no. 3, pp. 137-146, 2000.

[20] J. N. Fain, A. K. Madan, M. L. Hiler, P. Cheema, and S. W. Bahouth, "Comparison of the release of adipokines by adipose tissue, adipose tissue matrix, and adipocytes from visceral and subcutaneous abdominal adipose tissues of obese humans," Endocrinology, vol. 145, no. 5, pp. 2273-2282, 2004.

[21] B. D. Green, N. Irwin, R. S. Cassidy, V. A. Gault, and P. R. Flatt, "Long-term administration of PACAP receptor antagonist, PACAP [6-27], impairs glucose tolerance and insulin sensitivity in obese diabetic ob/ob mice," Peptides, vol. 27, no. 9, pp. 2343-2349, 2006. 


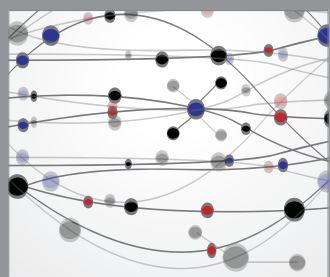

The Scientific World Journal
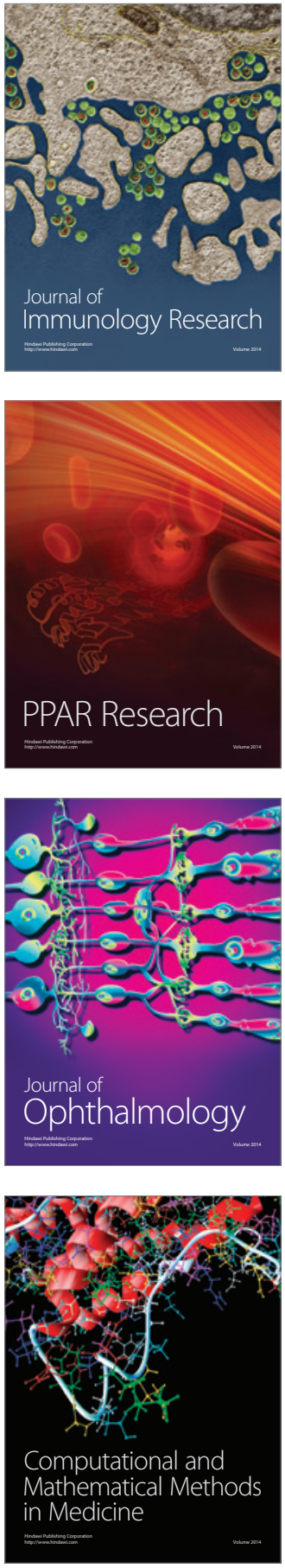

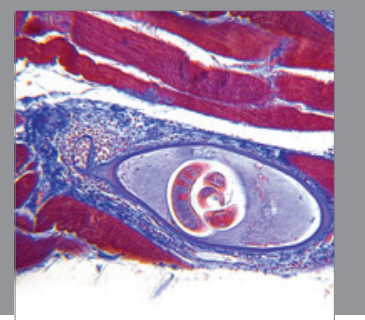

Gastroenterology

Research and Practice
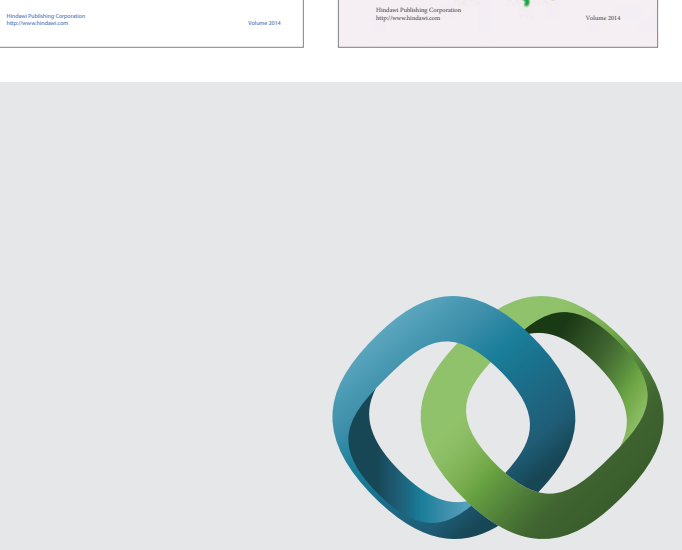

\section{Hindawi}

Submit your manuscripts at

http://www.hindawi.com
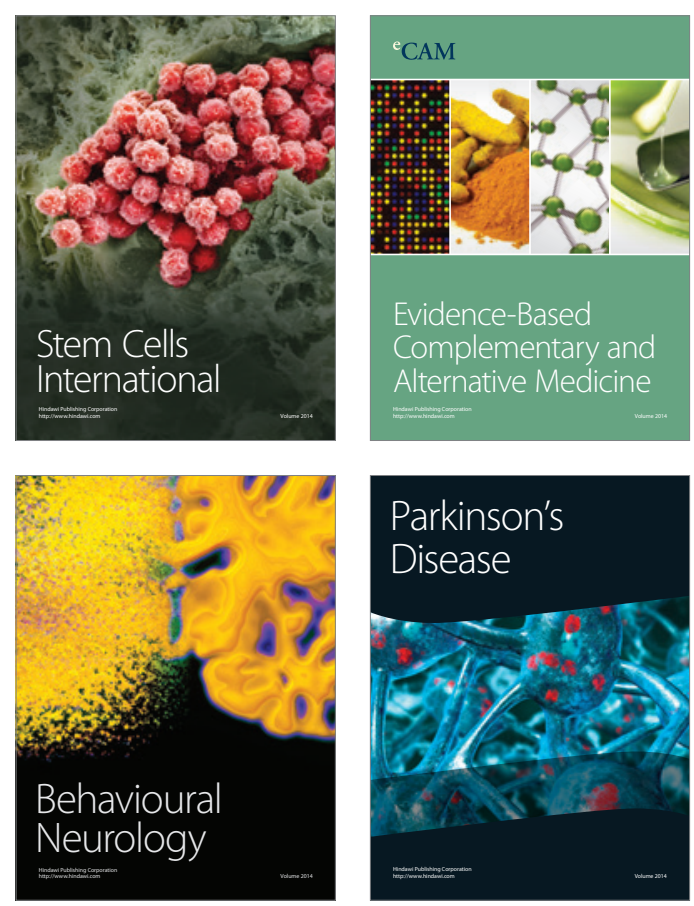

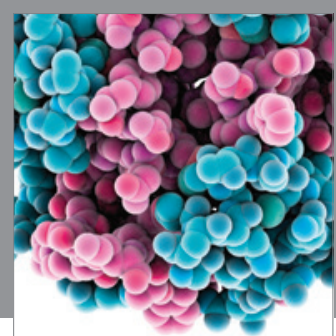

Journal of
Diabetes Research

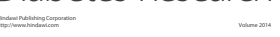

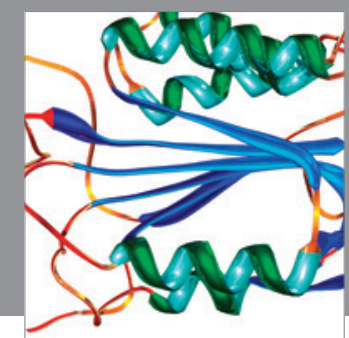

Disease Markers
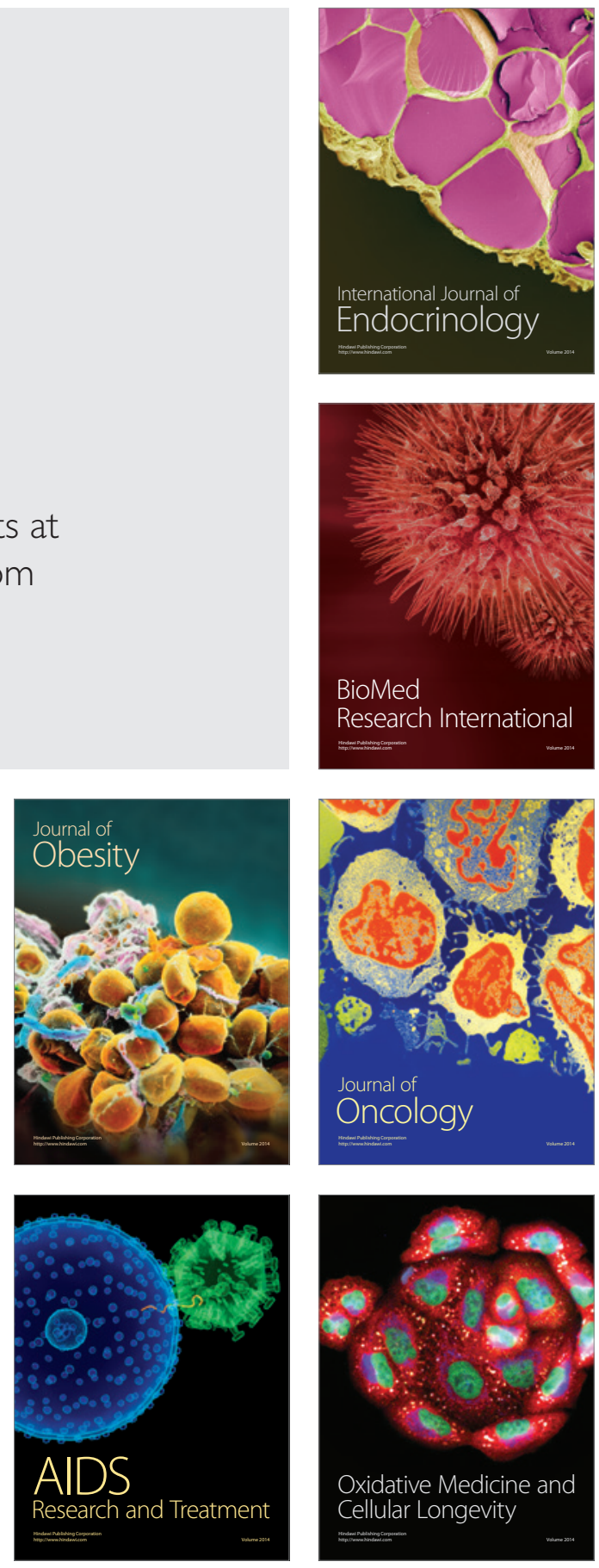